\title{
Application of Geostatistics in the Study of Ore-controlling Factors : Taking Example of Manjiazhai Ore Segment in Dulong Tin Polymetallic Ore Deposit
}

\author{
Fuju Jia ${ }^{1, a}$, Wu Wei ${ }^{2, b}$, Hongliang Nian ${ }^{3, c}$, Zize Xiao ${ }^{1, d}$ \\ ${ }^{1}$ Department of Earth Sciences, Kunming University of Science and Technology, Kunming, 650093, \\ China \\ ${ }^{2}$ Yunnan Metallurgical Group Co.,Ltd.,Kunming, 650224,China \\ ${ }^{3}$ Yunnan Institute of Nonferrous Metal No. 317 Geological Party, Qujing, 655000, China \\ aemail: jiafujv@163.com, bemail: 16580998@qq.com, 'email: 578961092@qq.com, 'email: \\ xiaozize2763149@126.com
}

Keywords: Geostatistics; 3D model; Tin Polymetallic Ore Deposit; Dulong Yunnan

\begin{abstract}
The the tin and zinc enrichment in the Manjiazhai ore segment ore-bearing strata were studied in this paper, Exploration samples database for 3D model was designed. Variogram analysis show that the strata ore-controlling characteristic is significant. Tin is mainly enriched in the lower layers and zinc is enriched in all layers of Manjiazhai ore segment.
\end{abstract}

\section{Introduction}

Dulong mining zone is in the southeast of Yunnan province, it's a part of Laojunshan metallogenic region where is rich mineral resources of tin, zinc, copper, silver and indium. Manjiazhai ore segment is at the center of Dulong tin polymetallic ore deposit. In this paper we will analysis the spatial distribution of tin and zinc elements in Manjiazhai ore segment, then combined with the study of geological characteristics to analysis ore-controlling factors of the ore segment.

\section{Geological setting}

Dulong mining zone is located at the southwest of South China fold system, in the south of Wenshan-Maguan uplift. Lower - middle Cambrian sedimentary is widely distributed in this region, regional geology with the characteristics of complex geological structures, and common existence of metamorphic rocks and strong granite magma activities.

Manjiazhai ore segment is at southwest of Laojunshan granite body. During the granite magma upward migration, serious of outward-dipping faults were formed around the granite body. Manjiazhai ore segment is in the southwest of the outward-dipping faults system. Orebodies in Manjiazhai ore segment occurrence in Middle Cambrian Tianpeng Formation( $\left.\in_{2} \mathrm{t}\right)$ mica-quartz schist and marble rocks. The strata strike north-south and dip 10-35 degrees to the west. The main ore-controlling factors are strata, structure and granite magma.

\section{Ore-bearing strata}

With the purpose to study the enrichment degree of tin and zinc, we had collected the two elements' environmental background values of China crust and no mineralized $\in_{2}$ t strata near the mining zone(Table.1). In the no mineralized $\in_{2} \mathrm{t}$ tin is 10.00 times and zinc is 2.45 times higher than these in the China crust. So tin and zinc had been enriched at a high level during the sedimentation of the Middle Cambrian Tianpeng Formation. 
Table.1. Abundances of tin and $\operatorname{zinc}\left(\times 10^{-6}\right)$

\begin{tabular}{ccc}
\hline Item & No mineralized $\in_{2} \mathrm{t}[1]$ & China crust[2] \\
\hline $\mathrm{Sn}$ & 41 & 4.1 \\
$\mathrm{Zn}$ & 211 & 86 \\
\hline
\end{tabular}

\section{D modeling}

The datas for 3D model are from the boreholes, trenches and tunnels. Tin and zinc are the main elements of the mining, and we selected the two elements as the research object. The exploratory grid in Manjiazhai ore segment were from $80 \mathrm{~m} \times 40 \mathrm{~m}$ to $40 \mathrm{~m} \times 40 \mathrm{~m}$, about 34000 samples were collected and imported the data into Surpac mining software, all the grade of samples were achieved 3D spatial orientation.

\section{Samples distribution}

In order to insure the distribution of the samples equally, we take $1 \mathrm{~m}$ as the standard unit, and divided about 48037 composited samples. The grade of tin samples: average $0.158 \%$, standard deviations 0.386, coefficient of variation 2.445. The grade of zinc samples: average 1.317\%, standard deviations 2.580, coefficient of variation 1.959. Tin samples show a logarithmic normal distribution, and zinc samples show approximately a logarithmic normal distribution, see Fig.1 (a) and (b).

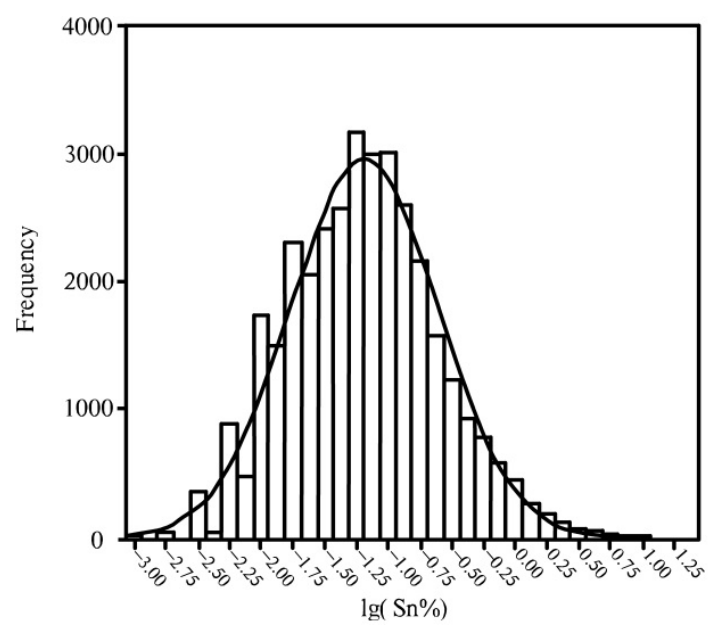

(a) Tin composited samples

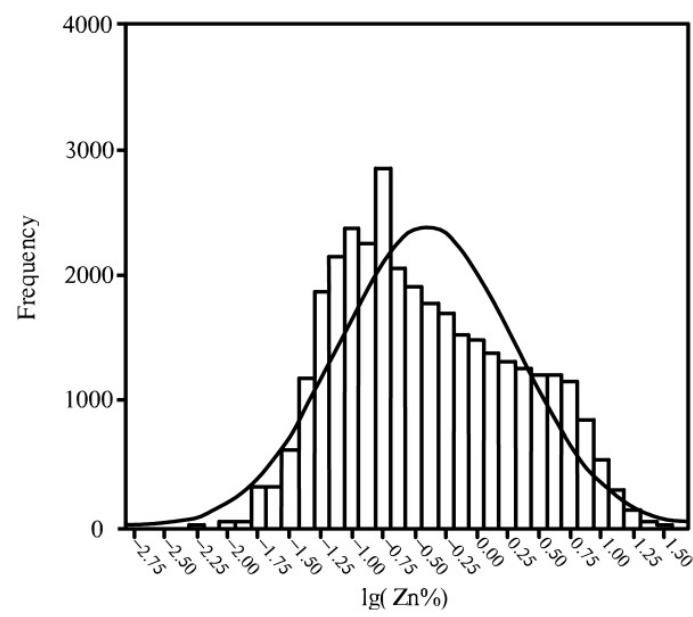

(b) Zinc composited samples

Fig.1. The statistical distribution

\section{Variogram}

Variogram is an useful tool to analysis the spatial structure, the regionalised variable investigated regarding small-scale heterogeneity (nugget effect), the strength of spatial structure(sill) and the distance beyond which samples become spatially independent (range) ([3]and [4]). After curve fit, test and verify the experimental variance function, the range can represent the continuity of the element grade at given direction, and the nugget represent variation of the element grade at given direction.

A total measurement of the main orebodies show that the along-strike as a direction of $0^{\circ}$ with a dip of $7^{\circ}$, down-dip as a direction of $270^{\circ}$, with the dips varying from $18^{\circ}$ to $33^{\circ}$, the average dip is $28^{\circ}$, and cross-orebody as approximately $90^{\circ}$ with a dip of $62^{\circ}$. Variogram was analysised by Surpac software, analysis results of the three directions show in table.2. 
Table.2. Variogram model parameters of tin and zinc

\begin{tabular}{l|lll}
\hline Element & Direction & Range $(\mathrm{m})$ & Nugget \\
\hline \multirow{3}{*}{$\mathrm{Sn}$} & Along-strike & 20.581 & 2.2337 \\
& Down-dip & 16.419 & 1.6670 \\
& Across the orebody & 13.876 & 0.1240 \\
\hline \multirow{3}{*}{$\mathrm{Zn}$} & Along-strike & 40.116 & 2.8715 \\
& Down-dip & 41.162 & 4.1988 \\
& Across the orebody & 14.359 & 2.7686 \\
\hline
\end{tabular}

Both tin and zinc have large range in along-strike direction, and zinc have maximum range in down-dip direction, indicate that the elements distributionin in that directions could be have better continuity than other directions. Tin have minimum nugget in across the orebody direction, means that tin grade have an uniform variation in the direction. Zinc have maximum nugget in down-dip direction, indicate that the zinc grade distribution is more non-uniform than other directions.

\section{Spatial distribution of tin and zinc}

No.67 section is in the center of Manjiazhai ore segment, we selected the samples in the section, after Special high grade replaced, the contour diagrams of tin and zinc were drawn. From Fig.2 and Fig.3 we can see that, tin is mainly enriched in the footwall layers of $F_{1}$ fault, and zinc is enriched in all the layers around $F_{1}$ fault.

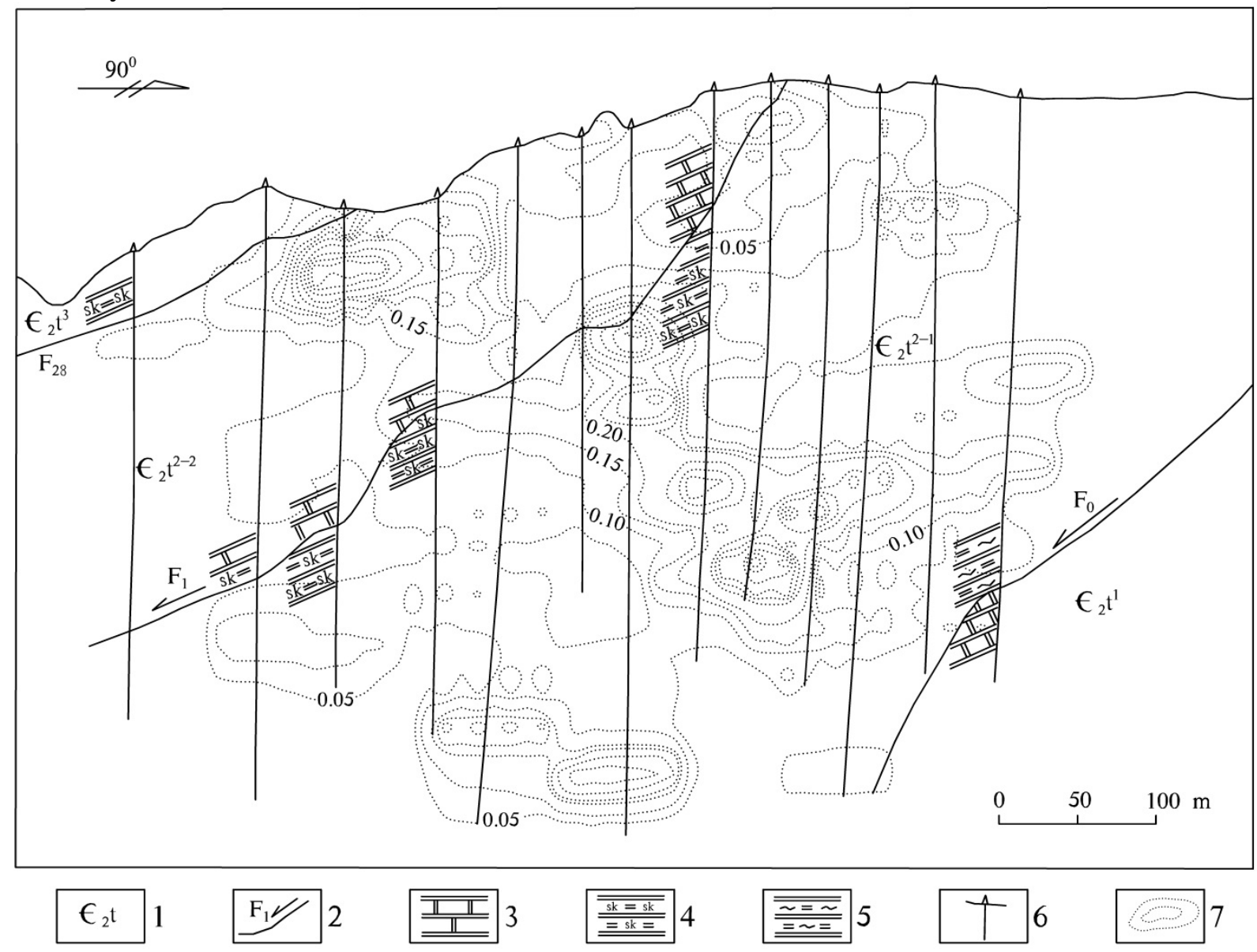

Fig.2. Contour diagram of tin in the No.67 section

1.Middle Cambrian Tianpeng Formation 2.Fault 3.Marble 4.Skarn 5.Gneiss 6.Drill 7. Isoline 


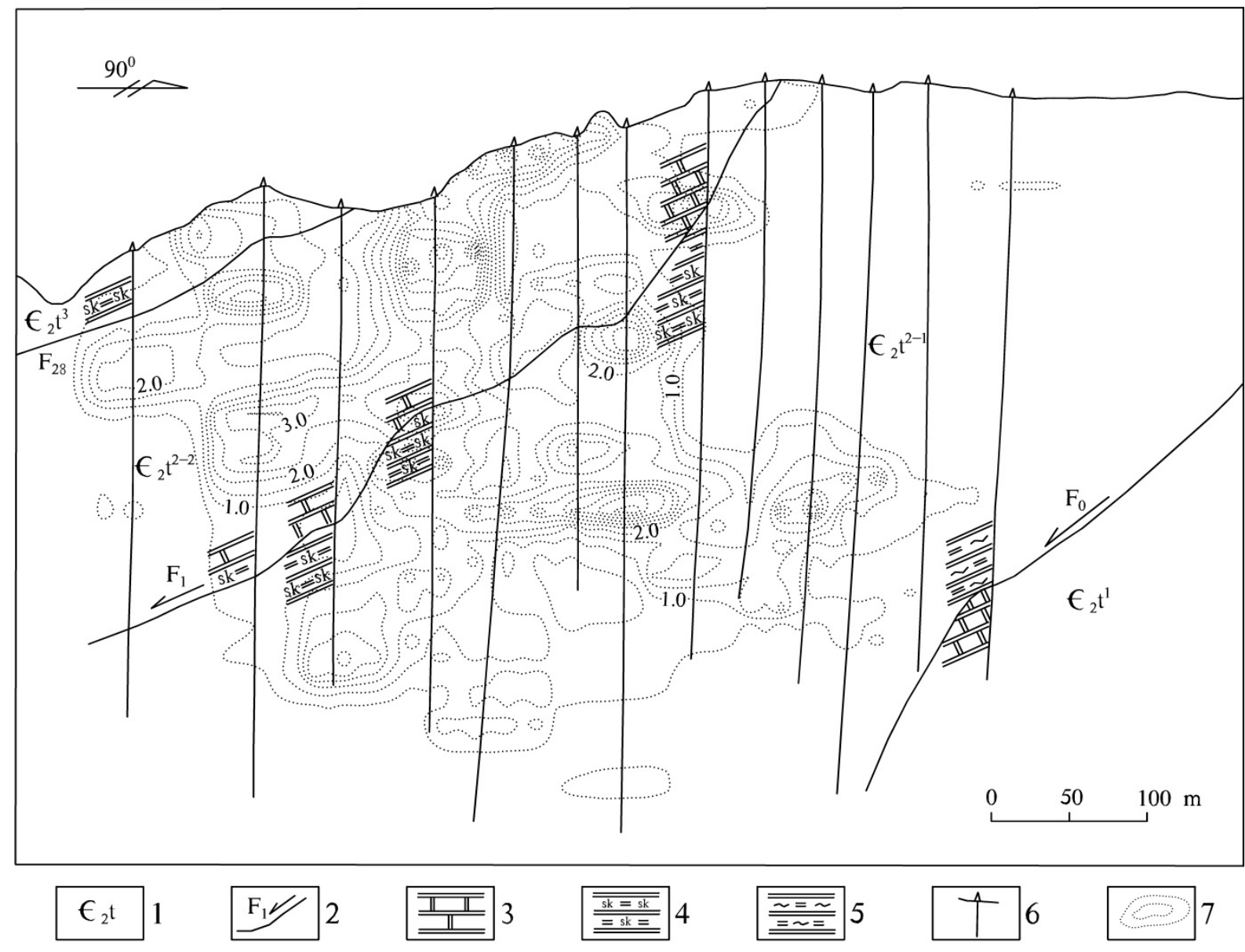

Fig.3. Contour diagram of zinc in the No.67 section

1.Middle Cambrian Tianpeng Formation 2.Fault 3.Marble 4.Skarn 5.Gneiss 6.Drill 7. Isoline

\section{Conclusion}

In Manjiazhai ore segment Middle Cambrian Tianpeng Formation have high levels of tin and zinc elements concentration, the main orebodies distribute along the strata, and strata ore-controlling characteristic is significant. Variogram analysis show that tin and zinc elements enrichment have good continuity in along-strike and down-dip directions, and this may caused by the process of metal elements depositing with the layer. Zinc grade is more non-uniform in down-dip direction, may influenced by the fault movement. Tin is mainly enriched in the lower layers and zinc is enriched in all layers of Manjiazhai ore segment.

\section{References}

[1] Yan Jian-guo. Geological Characteristics and Control Factors of the Dulong Tin-polymetallic Deposit in Yunnan Province. [J]. Southwest Mineral Resources and Geology. 1992(3)26-31.

[2] Li Tong and Ni Shou-bin. Element Abundances of China’s Continental Crust. [M]. Beijing: Geology Press, 1990.

[3] Clark.I. Practical Geostatistics. [M]. London: Appl Sci Publ, 1979.

[4] Carle,S.F. and G.E.Fogg. Modeling spatial variability with one and multidimensional continuous. [J]. Math.Geol, 1996 (7) 891-917. 